\title{
Erratum to: The activation of cultured keratinocytes by cholesterol depletion during reconstruction of a human epidermis is reminiscent of monolayer cultures
}

Évelyne De Vuyst ${ }^{1} \cdot$ Séverine Giltaire $^{1} \cdot$ Catherine Lambert de Rouvroit $^{1}$ Aline Chrétien ${ }^{2} \cdot$ Michel Salmon $^{2} \cdot$ Yves Poumay $^{1}$

Published online: 18 June 2016

(C) Springer-Verlag Berlin Heidelberg 2016

Erratum to: Arch Dermatol Res (2015) 307:309-318

DOI 10.1007/s00403-015-1537-3

In the original publication, in Fig. 1a, amount of cholesterol should be in $\mu \mathrm{g}$ (and not $\mathrm{mg}$ ) per epidermis.

The online version of the original article can be found under doi:10.1007/s00403-015-1537-3.

Yves Poumay

yves.poumay@unamur.be

1 URPHYM-Narilis, University of Namur,

61 Rue de Bruxelles, 5000 Namur, Belgium

2 StratiCell, 5032 Les Isnes, Belgium 
Fig. 1 Effect of incubation with $\mathrm{M} \beta \mathrm{CD}$ on the

concentration and localization of cholesterol in RHE analysed at day 5 of tissue reconstruction. a Cholesterol amount was quantified in RHE left untreated (before treatment and ctrl $24 \mathrm{~h}$ ) or in RHE incubated with $7.5 \mathrm{mM} \mathrm{M} \beta \mathrm{CD}$ for $1 \mathrm{~h}$ before different recovery periods $(0,1$, 4 and 24 h). Data are presented as means \pm SEM of three independent experiments; Anova1RM; Fischer-LSD test; $* p \leq 0.05$. b Frozen sections of RHE were stained with filipin and observed under a fluorescent microscope using UV wavelength as excitation light (DAPI filters). RHE was left untreated (MBCD-) or treated with $7.5 \mathrm{mM} \mathrm{M} \beta C D$ for $1 \mathrm{~h}(\mathrm{M} \beta \mathrm{CD}+)$ followed by different recovery periods $(0,1$, 4 and $24 \mathrm{~h}$ ). White dotted lines delineate the polycarbonate filter (scale bar $50 \mu \mathrm{m} ; n=3$ independent experiments)

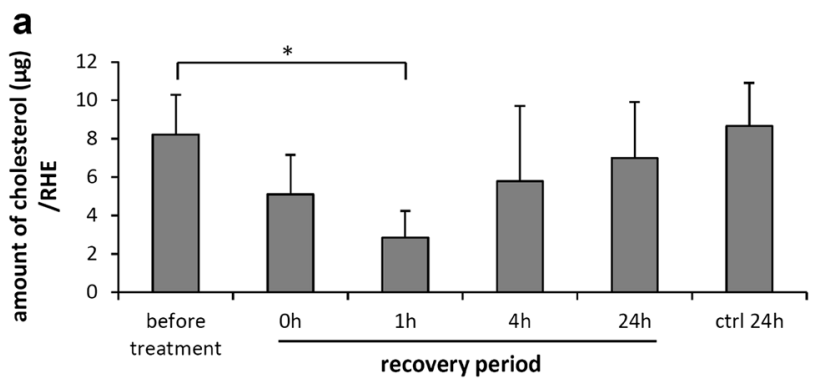

b

$M \beta C D-$
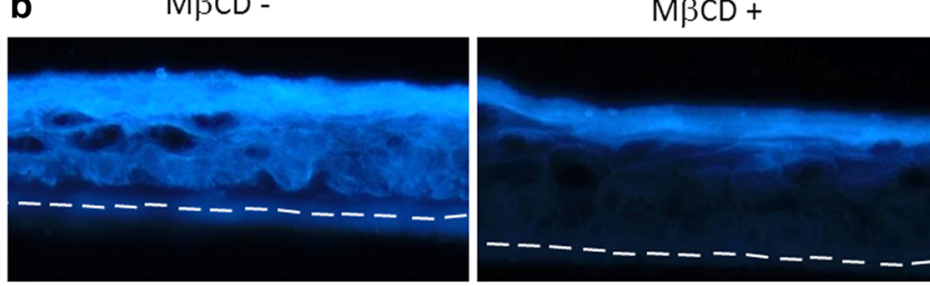

Oh

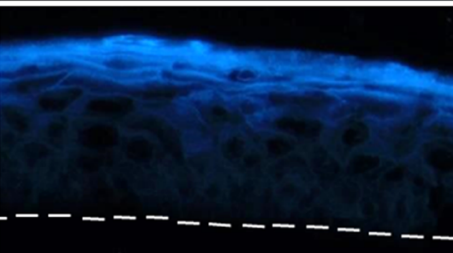

$1 \mathrm{~h}$

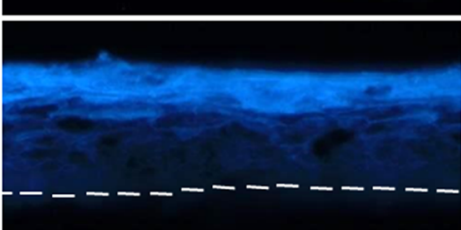

$4 \mathrm{~h}$
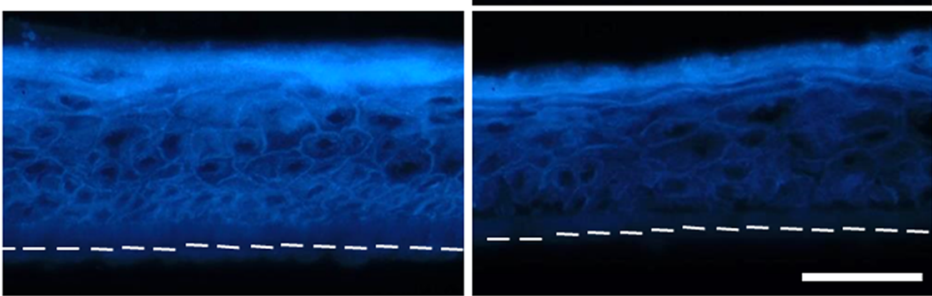